\title{
ARMONÍA Y RITMO EN ANTONIO COLINAS: AJUSTES MÉTRICOS EN NOCHE MÁS ALLÁ DE LA NOCHE
}

\author{
Por \\ José EnRiQue Martínez FernándeZ
}

$\mathrm{L}$

A obra toda de Antonio Colinas podría entenderse como la búsqueda de la armonía vital en consonancia con la armonía universal. La armonía (proporción, concordancia, etc.) alude en Colinas a una cierta plenitud vital, a la serenidad del ánimo, al equilibrio interior. Pero a medida que crecía la obra lírica y ensayística de Colinas, la armonía, sin perder las connotaciones anteriores, iba entendiéndose como conciliación de dualidades opuestas, impregnado como estaba el poeta del pensamiento taoísta y de la filosofía presocrática. Armonía no es ya sólo una idea o un anhelo, sino una manera de entender el mundo, la vida, el arte y la poesía. Digamos, sintéticamente, que para Colinas -siguiendo al primitivo pensamiento oriental- la armonía nace de la tensión de los contrarios. La dualidad (materia y espíritu, sueños y muerte, ser y no ser, lo diabólico y lo angélico, etc.) tiene para Colinas un sentido cercano a lo trágico. La dualidad perturba y desequilibra, siembra el desorden vital y universal. La aspiración suprema será, por lo tanto, la fusión de los extremos en unidad y armonía.

La búsqueda del equilibrio armónico es un deseo cada vez más acentuado en la obra de Colinas. De tal búsqueda derivan numerosos motivos que inspiran su poesía y que ha racionalizado en sus ensayos: la vuelta a los orígenes - cuando la poesía y la vida fueron armonía con el mundo y la Divinidad-; el sueño consiguiente con una Edad de Oro en la que el hombre vivía 
acorde con la naturaleza y el cosmos; el pensamiento ecológico como anhelo de recuperación de viejos valores armónicos, etc. El poeta ha señalado algunas vías hacia la conciliación de los contrarios, hacia la armonía: el amor, por ejemplo, como representación física de la idea de unidad, la mística, el silencio... y, de forma destacada, el arte, la música, la poesía: «El poema, el canto, la plegaria, la salmodia, la música, el ritmo, en una palabra, serán los medios para lograr esa armonía que la vida habitualmente no proporciona; o para contrarrestar la fuerza del terrible Hado» (Colinas, 2001c: 64). La cita podía proceder de un título representativo a este respecto: Tratado de armonía (1991), en el cual, sin olvidarnos del Nuevo tratado de armonía (1999), expuso Colinas, como él mismo ha escrito, su filosofía de la vida.

Colinas instituirá el mito de Orfeo como símbolo de la armonía universal. El poeta proyectará su obra lírica hacia el logro de la armonía órfica, por medio de la cual es posible traspasar las puertas que celan el misterio de la "segunda realidad". En este sentido, la "poética" de Colinas ha de colocarse bajo el signo de Orfeo, mito que acumula en sí el rico simbolismo de un pensamiento y de una obra poética coherentes: la armonía entre contrarios a través del canto y la poesía; el acceso a la otra realidad, cuyo símbolo es la noche, ámbito de los misterioso y desconocido, y fuente de revelaciones; la fusión de lo armónico y lo misterioso (canto y noche) en la música astral, idea de origen pitagórico; más allá, la noche mística es el símbolo último de la unidad armónica y de la plenitud. Es ésta una visión sucinta de lo que el mito de Orfeo ha venido a significar en la obra de Colinas y que ha cuajado con singular intensidad en composiciones como "Orfica", poema de Jardín de Orfeo (1988), dos títulos -el del poema y el del libro- bien significativos. Volcado el símbolo mítico hacia la poesía, Orfeo representaría el poder liberador de la palabra armónica, sujeta a medida e impulsada por un ritmo. Colinas se sentirá en profunda sintonía con aquellos poetas cuya lírica participa de este sentido órfico. Es el caso -por poner un único ejemplo- de Fray Luis de León y su "música razonada", 
es decir, sometida a "consonancia" y número", a "armonía" y "ritmo", términos que, al parecer de Colinas, resumen "el sentido órfico y pitagórico de la existencia" y de la poesía, "algo consustancial a la actitud de los poetas conscientes de habitar un cosmos" (Colinas, 1996).

\section{El ritmo respirado}

El equilibrio armónico, fruto de la fusión de las temidas dualidades, engendra un ritmo al que Colinas da un alcance cósmico, universal. Tal ritmo se manifiesta en la naturaleza, en el sucederse de los días y las estaciones o en los procesos de putrefacción y floración. En la naturaleza contempla Colinas numerosos signos de armonía; habría que aludir a los seres que la crean y propagan con sus vibraciones o sus cantos, seres a los que Colinas dota de distintos valores simbólicos: cigarras, grillos, ruiseñores, abubillas, lechuzas... Son ritmos de la constelación de la música, que es para Colinas el símbolo supremo de armonía y unidad y que inspira ideales de perduración, de eternidad. Pero ninguna de las manifestaciones naturales de la armonía y el ritmo ha adquirido tanta fuerza simbólica en Colinas como la respiración o «palabra en armonía». La respiración es - dice Colinas- «la unificación y la totalización ideal de la conciencia, de la experiencia física y de la aspiración hacia lo sublime». La respiración es, pues, un hecho real, creación continua, revitalización constante, la respiración pone al propio ser en contacto con lo de fuera y en ese contacto cobra aliento, vida; y acaso por eso es símbolo de fusión del pensar y del sentir, símbolo existencial y universal; símbolo de la poesía imbricada en la vida y en la realidad trascendida, pues respirar lleva consigo un ritmo, inconsciente, pero verdadero y continuo, uno de cuyos movimientos es la inspiración, que, en sentido profundo, define Colinas como «el ritmo de la palabra entre los labios, el ritmo del poema, el ritmo del verso»: «Nos acordamos del Todo cuando estamos inspirados. Y el que respira musicalmente con el verso respira infinito, funde los extremos. Callamos, respiramos, oímos la música inaudible...»; estamos a las puertas del misterio, donde, una vez más, «nos 
espera Orfeo con sus acordes» (Colinas, 1988: 30-32). En lo que tiene de ritmo, de equilibrio, de armonía, respirar es un símbolo del ámbito órfico que ha ido acumulando numeroso valores simbólicos: inspiración, ritmo, plenitud vital, armonía... ${ }^{1}$

Respirar llega a alcanzar un significado poético de gran alcance. La respiración es ritmo en sí misma; la palabra poética acaba contagiada por tal ritmo: «Inspiración y ritmo: he aquí dos claves decisivas para desvelar la creación poética, dos palabras que tienen mucho que ver con la respiración» (Colinas, 1991: 71). Pero el sentido del respirar trasciende el ritmo concreto del poema hacia la armonía universal, a la que la palabra rítmica, respirada, colabora: «El verso es la palabra originaria, fundadora, palabra que reproduce el ritmo del mundo. Por eso, al leer el verso, al respirar las palabras, respiramos el ritmo y la música del mundo. Y nuestro pecho se inflama entonces de eternidad musical» (Colinas, 1991: 37).

Estas ideas teóricas tuvieron concreción poética en el canto último (XXXV) de Noche más allá de la noche: en un lugar fundacional, primordial, "el centro del bosque", experimentamos la plenitud del ser, la Unidad del Universo, el sentirse uno con el Todo y Todo con el Uno, haciéndose con el respirar parte del Universo y haciéndose el Universo parte de uno, siendo el respirar (que es inspirar y espirar) verdadera unidad de opuestos:

Me he sentado en el centro del bosque a respirar.

He respirado al lado del mar fuego de luz.

Lento respira el mundo en mi respiración.

En la noche respiro la noche de la noche.

[...]

Inspirar, espirar, respirar: la fusión

de contrarios, el círculo de perfecta consciencia.

Sobre este canto ha escrito Colinas que «la respiración -la rítmica del poema y la física del protagonista del mismo- es la

${ }^{1}$ «¿Cuál es la razón más poderosa para vivir? Sin duda, el respirar conscientemente. La respiración es uno de los escasísimos bienes que nos conducen gratuitamente a la armonía» (Colinas, 1991: 19). 
clave del mismo. En esa respiración -clave, a su vez, del ser- se unifica el inspirar y el espirar, se unifican los contrarios y se logra la plenitud» (Colinas, 2001d: 121).

Llevadas estas ideas a la poesía, Colinas no es menos trascendente: «Respirando con el ritmo del poema, existimos en el más alto grado de consciencia y buscamos la liberación» (Colinas, 1988: 32); pero cuando se ciñe al texto poético, respiración y ritmo son conceptos tan próximos y hechos físicos tan concordes que se necesitan el uno al otro: «La respiración va unida al leer el poema. Leemos el poema en la medida en que respiramos de cierta manera [...]. La respiración de la dicción unida al ritmo del texto, acompasado con la respiración» (VV.AA., 1994: 70).

El ritmo del texto, dice el poeta. No se ha prodigado Colinas a la hora de exponer determinados aspectos métricos de la poesía (y de su poesía), probablemente porque, al fin, el ritmo del poema, no es más que una manifestación de la armonía que rige el universo. Sin embargo, el ritmo es consustancial a la poesía, como no podía ser de otra manera en un pensamiento órfico que da a la palabra y al canto, a la poesía y a la música -al ritmo-un sentido trascendente. ${ }^{2} \mathrm{Si}$ es consustancial a la poesía, el ritmo será cimiento del poema versificado, sea en versos canónicos o en versos libres, a la vez que será el signo distintivo de la poesía frente a la prosa. De ahí que Antonio Colinas -traductor experimentado de poetas como Leopardi, Quasimodo, Sanguineti y otros- entienda que salvaguardar el ritmo es la única manera de salvaguardar la poesía traducida. ${ }^{3}$ Lo único que pide al ritmo es que sea natural, no forzado, expresivo, no mecánico, connatural al poema: «El ritmo del poema -su música- es la característica primera, suprema, de la poesía. En consecuencia -a veces, no siempre- métrica y rima juegan un papel decisivo en la calidad

$\overline{{ }^{2} \text { La }}$ música y la poesía «¿no son, en último extremo, lo mismo en la confluencia del ritmo? [...]. Poesía y música vienen determinados en lo fundamental por el ritmo, y de sutiles y entramados ritmos - unas veces positivos (la armonía), otras negativos (el caos)- parece estar hecha la existencia» (Colinas, 2001e: 14).

${ }^{3}$ «Raramente se mantiene la poesía de un texto si no se salva su ritmo, que a su vez es la característica esencial, imprescindible, de la creación poética. Podemos disponer de una traducción fiel a la forma y al contenido de un poema, pero si no mantiene el ritmo siempre será incompleta» (Colinas, 2001f: 54). 
del poema. Lo que sucede es que ese ritmo debe ser algo natural, espontáneo, nunca forzado» (Colinas, 1997). El ritmo es lo que hace que el verso libre sea verso y no "prosa cortada": «El verso libre es tan válido como el medido -siempre que tenga ritmo», dice Colinas, que al abuso del verso libre, a «tanta prosa cortada», opone el antídoto machadiano: «verso libre, verso libre, / líbrate mejor del verso / cuando te esclavice» (Colinas, 1997). Respecto a la diferencia verso-prosa, declarará el poeta:

Sabemos de la importancia del ritmo del poema, de la poesía; hasta el extremo de que me parece que el ritmo es lo que -sustancialmente- diferencia a la poesía de la prosa. Muchas veces digo que ante un mal poema hay que hacer un experimento, y es poner los versos uno detrás del otro, como si fuera prosa. Si el poema no es auténtico, queda automáticamente destruido. El ritmo es una de las constantes más decisivas del poema (VV.AA., 1994: 67).

En otra ocasión añadirá al ritmo otra característica más frente a la prosa y la "prosa cortada": el ser palabra nueva, es decir, creada por vez primera, palabra que conmueva por su novedad, reveladora, palabra que estimule y provoque, palabra polisémica y metamorfoseadora de la realidad:

La poesía no sólo se distingue de la prosa por su disposición vertical -como creen algunos pillos de la poesía-, es decir, por cortar las frases como quien las corta con tijeras para colocarlas unas debajo de otras a modo de poema. La palabra en el poema tiene que tener su ritmo, tiene que ser algo nuevo para que se distinga no ya de la prosa poética, sino de lo que es simplemente prosa (Colinas, 2001g: 271).

Colinas encontró un vocablo resumidor de las características de la palabra nueva: voltaje, término que toma de Ezra Pound y que ha interpretado como "sobrecarga emotiva". El voltaje es lo que proporciona emoción, intensidad, pureza formal, ritmo y musicalidad, que son cualidades que Colinas, reiteradamente, pide a la verdadera poesía. «La palabra poética -ha escrito Colinas (2001h: 31)- se distingue de la prosa no sólo por su 
disposición vertical, sino [...] porque desea ir más allá. Porque tiene una intensidad y un 'voltaje' que no posee en otros géneros», es decir, porque es palabra emotiva, rítmica, intensa, nue$v a$. No es raro, por otra parte, que la crítica haya subrayado en la propia poesía coliniana las características señaladas u otras semejantes: claridad expresiva, luminosidad, pureza, belleza formal, delicadeza, suavidad, equilibrio entre novedades formales y prosaísmo, entre excesos formalistas o contenidistas, emoción, lirismo, etc. Así, José Luis Puerto, por poner un único ejemplo, dirá de Colinas que «su voz lírica trajo consigo a la poesía española una nueva música llena de emoción y de pureza, nacida del equilibrio entre lo clásico y lo romántico» (Puerto, 1997a: 41).

Hay dos palabras próximas semánticamente: ritmo y musicalidad. No son sinónimas, sin embargo: «El ritmo (y por extensión, la musicalidad) es la clave del verso, de la poesía» (Puerto, 1997b: 157). Si no entiendo mal, el ritmo del poema concreto vendría dado por elementos de carácter métrico básicamente. Al ritmo contribuiría, además, la sensibilidad especial para disponer armónicamente en el poema fenómenos fónicos y semánticos que lo dotarían de esa musicalidad que incluye al ritmo y que hace que podamos atribuir al poema la belleza formal, la suavidad y el lirismo con que ha sido caracterizada la poesía de Colinas.

\section{El alejandrino coliniano. Noche más allá de la noche}

A lo largo de su obra lírica, Antonio Colinas se ha sentido cómodo, especialmente, dentro del marco del endecasílabo y del alejandrino, como si fueran metros que se acoplaran de modo natural a la manera de ser de su poesía.

La medida -tal como yo la utilizo- ha sido bastante natural. Es decir, nunca me he propuesto medir las sílabas con los dedos y forzarlas, forzar la creación del poema medido, sino que el poema respondiera a un ritmo. Uno de los ritmos más clásicos, que a mí me gustan más, son los del alejandrino y el endecasílabo (VV. AA., 1994: 67). 
Colinas dice lo anterior aludiendo a Noche más allá de la noche (1983) y a Jardín de Orfeo (1988). Al primero de estos libros es al que van a referirse las páginas que siguen.

Noche más allá de la noche -cuyo título, verdadero emblema de las pretensiones poéticas de Colinas, procede de la quinta de las Elegies de Bierville (1943) de Carles Riba: «nit mes enllà de la nit»- consta de treinta y cinco cantos numerados en romano y sin título, con veintiocho versos cada uno, más un "Post-scriptum" de veinte versos: mil alejandrinos en total. Los cantos están compuestos en versos alejandrinos blancos, con la excepción de los cantos I, VI, XI, XIV, XV, XVI y XXXIII, que son una sucesión de serventesios, siempre en versos alejandrinos.

Ni el uso del alejandrino ni el libro entero en dicho metro eran novedad en la obra de Colinas. Ya su primer poemario publicado, Poemas de la tierra y de la sangre (1969), estaba compuesto todo él en versos alejandrinos y, salvo el poema V, "Barrios de luna" - de tipo arromanzado, con asonancia en los versos pares-, en alejandrinos blancos. Después, Preludios a una noche total (1969) combina poemas en endecasílabos (once en total) con poemas en alejandrinos (en dieciocho de las composiciones), y todos ellos en versos blancos a excepción de "Espeso otoño", con asonancia arromanzada. El predominio de poemas en endecasílabos (diez en total) y en alejandrinos blancos (siete composiciones) prosigue en Truenos y flautas en un templo (1972), libro en el cual hay ya distintas composiciones de un versolibrismo moderado que volveremos a encontrar en los dos poemarios siguientes, Sepulcro en Tarquinia (1975), con cinco composiciones en alejandrinos blancos -contando como tal "Noviembre en Inglaterra", cuyo último verso es un heptasílabo- y Astrolabio (1979), con siete (contando entre ellos "La patria de los tocadores de siringa", poema de cincuenta y cuatro versos, todos ellos alejandrinos a excepción de un heptasílabo y las variaciones I y VIII, de las diez de que consta la serie titulada "Variaciones sobre una suite castellana").

Son los poemarios que desembocan en Noche más allá de la noche, probablemente la obra de mayor altura de la lírica 
coliniana, a la vez que la más compleja, por lo que ha suscitado distintas interpretaciones -el propio Colinas (2001d) ha ofrecido algunas claves de lectura- en las que no vamos a entrar, con el fin de centrarnos únicamente en el uso del alejandrino en dicho poemario.

Como ya indicamos, la novedad no residía, métricamente, en que todo un poemario estuviera compuesto en alejandrinos, sino en mantener un ritmo sostenido a lo largo de mil versos justos. Colinas ha insistido en la acomodación natural a dicho metro: «Yo he escrito buena parte de mi obra en endecasílabos y en alejandrinos -mi libro Noche más allá de la noche consta de mil alejandrinos-, pero porque así me lo pedía el ánimo, la "música" interior que había en mí, y no por un propósito previo» (Colinas, 1997).

Esta necesidad interior de expresarse en un metro determinado, como forma natural de fluencia rítmica, ha sido cuestionada - pensando sobre todo en Noche más allá de la noche- por críticos como Luis Miguel Alonso Gutiérrez (2000: 40-41), que habla del propósito definido de estructuración métrica y estrófica de dicho poemario: «Es obvio que, ni la regularidad de los versos, ni la cifra que alcanza su suma, pueden ser debidas a algo que no sea un plan, plan que fue ajustando las unidades métricas de los Cantos a aquella estructuración». Y cita como testimonio que avale su tesis el análisis que Caravaggi (1990) llevó a cabo del proceso de creación del canto VII a través de las sucesivas versiones del mismo, hasta llegar a la solución final en alejandrinos; comenta el crítico italiano respecto a la última versión:

La quarta documenta una ristrutturazione globale, anche ritmicamente determinante, poiché si passa da una scansione polimetrica, in cui dominano gli endecasillabi in alternanza con settenari o altri versi, ad una scansione più uniforme e pausata di alessandrini.

Tal hecho parece indicar «una vicenda creativa assai elaborata» (Caravaggi, 1990: VI).

La crítica no se ha detenido demasiado en el análisis de la métrica coliniana, si no es para establecer generalidades u obviedades. Por lo que respecta a Noche más allá de la noche, la 
organización metódica del libro ya mentada y la cifra emblemática de los mil versos llamaron más la atención que el metro empleado. Pero hay algunas excepciones. Así, Rosa María Pereda (1983) escribe, en crítica de urgencia, sobre el "tratamiento del alejandrino" en la poesía española moderna y en el propio Colinas:

Que no espere el lector el ritmo clásico, porque justamente es lo que se rompe. Que no mida con los dedos, porque la cesura, que no tiene por qué ser una sola en el verso y tampoco tiene por qué existir, va a forzar los ritmos acentuales [...]. La tensión también se siente en la sintaxis misma, en la descoincidencia entre la frase y el verso, que produce encabalgamientos a veces violentos.

Tal tensión sería una muestra externa de la existente entre sentimiento y razón, en una pugna feliz cuyo producto definitivo es esta Noche más allá de la noche.

Por su parte, Alonso Gutiérrez (1990: 89) asevera:

Los mil alejandrinos de Noche... subrayan con su pausada solemnidad la grave importancia de lo que en ellos se dice. Pero no se imagine aquí la expresión coartada por una rígida estructura poética. Colinas rompe con el ritmo clásico al situar irregularmente la cesura en el verso.

¿Irregularmente? No parece que sea así, sino conforme a la forma tradicional del alejandrino, si atendemos a la nota al pie que añade el citado crítico:

Para ser más precisos, es la cesura medial la que -llevando a leer cada uno de los hemistiquios como si fueran secciones métricas heptasilábicasconvierte en alejandrinos algunos versos que, por simple cómputo métrico serían tridecasílabos o pentadecasílabos (Alonso Gutiérrez, 1990: 89).

El crítico ejemplifica lo dicho con primeros hemistiquios terminados en aguda o en esdrújula y que se equiparan a la terminación llana; pero los alejandrinos compuestos por dos hemistiquios de $7+7$ sílabas, con el primero siempre acentuado en 
sexta sílaba, y separados por pausa que funciona como la pausa final de verso -es decir, sin sinalefa entre las sílabas métricas séptima y octava y con finales llanos, agudos y esdrújulos equivalentes- es tradicional en la métrica española desde Berceo. De ahí la "disposición muy clasicista" del canto X -y de todos los restantes, en este sentido- cuyo "perfecto ajuste rítmico" analizó Huerta Calvo (1997: 214-218): veintiocho versos alejandrinos divididos en dos hemistiquios heptasilábico separados por cesura intensa con las diferentes posibilidades acentuales que dan a tal tipo de verso su peculiar polirritmia. El análisis es extensible al resto de los cantos de Noche más allá de la noche. Como veremos, Colinas, en las variantes introducidas en sucesivas ediciones del poemario y, sobre todo, en la última de ellas (2004) ha intentado un acoplamiento mayor del ritmo del alejandrino al ritmo del metro tradicional de dicho verso. Parémonos previamente en algunas opiniones del poeta sobre sus propios versos alejandrinos:

Aunque parece que soy un poeta muy formal, soy también un poco escéptico sobre la forma. No soy excesivamente purista. Hago un tipo de alejandrino en el que la cesura está muy marcada; en realidad son dos versos de siete sílabas. Algunos puristas dicen que el alejandrino tiene que ser un verso más enlazado, más flexible. Pero, en fin, nunca he seguido criterios de estricta pureza en esto (VV. AA., 1994: 68). ${ }^{4}$

${ }^{4}$ Añade Colinas que Antonio Tovar, en reseña de Sepulcro en Tarquinia (alude a la publicada en Gaceta ilustrada, 28-08-1976) le hizo ver que el extenso poema de igual título contenía tres endecasílabos mal acentuados: «No sé si, en algún caso, se me había ocurrido reparar en ello, pero tampoco lo he corregido luego [...]. Recuerdo uno de aquellos endecasílabos, uno de los mal acentuados, el formado por cuatro nombres de músicos: "Vivaldi, Telemann, Lentz, Scarlatti". Había que leer Telemánn, ¿no? Pues si leyéramos Télemann estaría mal acentuado el endecasílabo [...]. Lo mismo sucedía en el heptasílabo "Oh misterium fascinans", el poema que va al final de Sepulcro, el que cierra el libro. Una opinión para mí valiosa, ¿no?, la de Tovar, aunque extremada» (VV. AA., 1994: 68). Lo cierto es que Colinas acabó corrigiendo el endecasílabo citado: "Vivaldi, Telemann, Lentz, Scarlatti" derivó hacia "Lentz, Scarlatti, Telemann, Vivaldi" desde la edición de Sepulcro en Tarquinia en Poesía, 1967-1981 (1994. Madrid: Visor), con acentuación en sexta sílaba. «¡Oh misterium fascinans!» se mantuvo como tal hasta la edición de Sepulcro en Tarquinia en 2004, dentro del libro En la luz respirada (Madrid: Cátedra), en que el verso se transforma en «jfascinante misterio!». 
Uno de los contertulios le hace ver a Colinas que algunos presuntos alejandrinos de Noche más allá de la noche son dodecasílabos; pone como ejemplos dos versos del canto XXXV: «que inspira la luz y espira la sombra» $\mathrm{y}$ «que inspira la vida y espira la muerte»; y Colinas aclara: «Allí rompo la sinalefa; es otra libertad que me tomo. Este alejandrino consta pues de dos versos de siete sílabas, porque al sumar una sílaba más a luz hay siete sílabas» (VV. AA., 1994: 68). Sin embargo, para la edición de Noche más allá de la noche, dentro de En la luz respirada (2004), los versos fueron corregidos por el autor: «que inspirando la luz va espirando la sombra / [...] que inspirando la vida va espirando la muerte». Esto quiere decir que Colinas ha ido ajustando el ritmo de los alejandrinos de Noche más allá de la noche por medio de correcciones que se han multiplicado en la edición última citada, la publicada, con otros dos libros de Colinas, bajo el título de En la luz respirada, en adelante LR.

Para dicha edición, el poeta revisó los diferentes cantos de Noche más allá de la noche e introdujo numerosas correcciones cuyo escaso relieve semántico contrasta con el acompasado ritmo que el poeta ha buscado con ahínco.

Pocas son, por lo tanto, las correcciones ajenas a lo métrico. En tales casos se trata, por lo general, de variantes estilísticas de las que pondré tres ejemplos:

Canto XIII, v. 17: ayuda a la razón. Los dos vagaron luego

ayuda a la razón. Ambos vagaron luego (eds. anteriores)

En realidad, la nueva variante de LR evita dos acentos consecutivos: razón-ámbos: el de la última palabra sería un acento antirrítmico, si seguimos a Balbín.

Canto XXVIII, v. 9:me escarnece a través de un cosmos espinoso (LR)

me escarnece a través de un espinoso cosmos (eds. ants.)

La variante de LR evita la cacofonía de cuatro vocales $o$ consecutivas: espinoso cosmos. 
Canto XXXIV, v. 8: que en sí mismo provoca la dilatada luna? (LR)

que en sí mismo provoca la dilatada noche? (eds. ants.)

La variante luna huye de la reiteración de noche, que aparece en el verso siguiente: «Mas incluso en la noche hay arpones de luz».

En su gran mayoría las variantes tienen una función rítmica. El alejandrino coliniano responde al canon tradicional, con cesura intensa entre los dos hemistiquios heptasilábicos, de forma que tal cesura afecta al primer hemistiquio igual que la pausa al segundo; tal cesura impide la sinalefa entre los hemistiquios y hace que los finales agudos, llanos y esdrújulos sean equivalentes. Pero a lo largo de Noche más allá de la noche, y fuera de la cesura intensa Colinas prescindía de la sinalefa, a favor del hiato, en numerosísimas ocasiones, forzando acaso el ritmo normal del alejandrino, como puede observarse en estos cuatro versos (13-16) del canto VI ( $1^{\mathrm{a}}$ ed.):

¿Recordáis aún los muertos? / ¿Cuál es la escritura absoluta del hombre / cuando va a morir? ¿Y cuál es el lenguaje / inscrito en la dura realidad por la sangre / con su cerrado fluir?

Todas las correcciones no meramente estilísticas que Colinas introduce en dicho poemario para la edición de LR pretenden ajustar el ritmo del alejandrino a la pronunciación habitual castellana, por más que no olvidemos lo que la sinalefa pueda tener de convención métrica, como ha recordado Domínguez Caparós (1993: 68). Véase el acomodamiento rítmico al que Colinas ha sometido los cuatro versos citados:

¿Recordáis aún los muertos? / ¿Y cuál es la escritura absoluta del hombre / cuando se va a morir?

¿Y cuál es el lenguaje / que se inscribe en la dura realidad por la sangre / con su cerrado fluir?

En realidad, en las sucesivas ediciones de Noche más allá 
de la noche Colinas había efectuado ya, aunque tímidamente, algunas escasas correcciones en tal sentido. Es para la edición del libro en LR cuando emprende una laboriosa tarea de arreglo rítmico cuya función es en todos los casos la misma: ajustar los hemistiquios de cada verso silábicamente, de forma que los hemistiquios que antes podían tener siete sílabas o menos, según se realizaran o no las posibles sinalefas, sean ahora heptasílabos cabales. Se trata, por lo tanto, de guardar las reglas métricas más comunes en el cómputo silábico, pero no por mero afán formal, sino con el propósito de lograr un ritmo más armónico y cadencioso.

Las correcciones que introduce Colinas pueden clasificarse conforme a tres de las categorías modificativas: adición, sustitución e inversión del orden de los elementos lingüísticos. Puede decirse que no hay omisión neta de elementos si no es combinada, por ejemplo, con la adición de otros, como ocurre en el canto XXXV, en que se suprime yo, pero se añade al fin, o con la inversión de elementos, como ocurre en el canto XVII:

Canto XXXV, v. 13: Y era, al fin, un gran sol de luz que respiraba (LR)

Y yo era un gran sol de luz que respiraba (eds. ants.)

Canto XVII, v. 11: que sepultaba un sueño de cadáveres, de oros (LR)

que sepultaba un sueño de oros y cadáveres (eds. ants.)

Las variantes por sustitución son las más numerosas; siguen las de adición y, finalmente, las de inversión.

Las correcciones por sustitución se acercan al centenar (más de ochenta). Hallamos cambios entre formas de un mismo verbo, que en la nueva variante suele introducir alguna sílaba más que regulariza cada hemistiquio en las siete sílabas métricas exactas. Así ocurre, por ejemplo, cuando el poeta sustituye enraizaba por iba enraizando (lo que evita la diéresis primitiva de enraïzaba), ardía por iba ardiendo (que evita el hiato primitivo entre alláarriba o arriba-ardia), hubo por ha habido (que elimina el hiato 
entre siempre-hubo), veré a por podré ver (que elimina la innecesaria preposición $a$, que sólo estaba presente para regularizar, con hiato, el heptasílabo) e inspirar y espira por inspirando y va espirando respectivamente, que, además del ajuste silábico, da rotundidad sonora a los versos correspondientes:

Canto VI, v. 7: cuando en tu propio cuerpo iba enraizado el hado (LR)

cuando en tu propio cuerpo enraizaba el hado (eds. ants.)

Canto IX, v. 16: Y, allá arriba, iba ardiendo en luz de oro el mundo (LR)

Y allá arriba ardía en luz de oro el mundo (eds. ants.)

Canto IX, v. 19: que siempre ha habido en mí, pero yo era lo blanco (LR)

que siempre hubo en mí, pero yo era lo blanco (eds. ants.)

Canto XV, v. 21: Y podré ver los álamos recibir la nevada (LR) Y veré a los álamos recibir la nevada (eds. ants.)

Canto XXXV, v.15: que inspirando la luz va espirando la sombra (LR)

que inspira la luz y espira la sombra (eds. ants.)

v. 17: que inspirando la vida va espirando la muerte (LR)

que inspira la vida y espira la muerte (eds. ants.)

El cambio de un singular (el verdor) por un plural (los verdores) privilegia la sinalefa (de-Al-Ándalus) frente al hiato (de-AlÁndalus) o elimina el hiato en el segundo ejemplo:

Canto XIX, v. 4: brilla toda la vida, los verdores de Al-Ándalus (LR) brilla toda la vida, el verdor de Al-Ándalus (eds. ants.)

Post-scriptum, v. 6: sangre y labio retienen las horas fugitivas (LR)

sangre y labio retienen la hora fugitiva (eds. ants.) 
Algo semejante ocurre en el cambio de un masculino (el mar) por un femenino (la mar) que elimina el hiato primitivo:

Canto VI, v. 22: y, de día, la mar que devoró los besos (LR) $\mathrm{y}$, de día, el mar que devoró los besos (eds. ants.)

La sustitución afecta en numerosos casos a palabras sinónimas o próximas semánticamente dentro del contexto; entre los muchos ejemplos que podrían ponerse, basten los siguientes:

Canto II, v. 4: mientras llega del fondo de la noche y su nada (LR)

mientras llega del fondo de la noche y su aire (eds. ants.)

Canto II, v. 14: Algo devora al alma en su inmovilidad (LR)

Algo absorbe al alma en la inmovilidad (eds. ants.)

Canto XV, v. 4: y pureza eternal en todo cuanto tocas (LR y eds. posteriores a la primera)

y pureza eterna en todo cuanto tocas $\left(1^{\mathrm{a}}\right.$ ed.) (LR)

Canto XV, v. 14: pero siempre tan puro a la hora del ensueño pero siempre tan puro a la hora del sueño (eds. ants.)

Canto XXI, v. 3: Mas la mente aún se encuentra muy lejos del jardín (LR)

Mas la mente aún se halla muy lejos del jardín (eds. ants.)

Canto XXII, v. 9: Es un dolor que entreabre la piedra de los muros (LR)

Es un dolor que abre la piedra de los muros (eds. ants.)

Canto XXVI, v. 25: y es sabio al susurrar, mientras ve entre los árboles (LR) ants.)

$\mathrm{y}$ es sabio al decirse, mientras ve entre los árboles (eds.

Canto XXX, v. 2: Entre verdosos tesos de heladoras herrumbres (LR) 
Entre verdosos tesos de heladas herrumbres (eds. ants.)

Canto XXXIII, v. 19:que enamoran o abrasan, sin que consiga el uno (LR)

que enamoran o abrasan, sin que logre el uno (eds. ants.)

Canto XXXIV, v. 10: congelada en lo negro, clavados en la muerte (LR)

helada en lo negro, clavados en la muerte (eds. ants.)

Post-scriptum, v. 12: se forman y deshacen quemados por el tiempo (LR)

se hacen y deshacen quemados por el tiempo (eds. ants.)

Los casos más abundantes de sustitución se dan, sin embargo, entre partículas; de los cerca de cincuenta que podríamos traer a cuento damos sólo una muestra significativa: se trata, por ejemplo, de sustituir en, frecuentemente en hiato con la palabra precedente, por con, que no permite hiato ni sinalefa, o bien, de que una palabra bisílaba sustituya al anterior monosílabo (esta por la, sobre por en, desde por de, etc.) para ajustar cabalmente la medida el hemistiquio heptasilábico:

Canto IV, v. 4: Se había quedado quieto el tiempo en esta orilla (LR)

Se había quedado quieto el tiempo en la orilla (eds. ants.)

Canto VIII, v. 7: sobre la isla de Circe, quiso ir más allá (LR) en la isla de Circe, quiso ir más allá (eds. ants.)

Canto XII, v. 22: de este monte, más gritos en su pétrea entraña (LR)

de este monte, $y$ gritos en su pétrea entraña (eds. ants.)

Canto XVI, v. 25: Herida sobre herida, negrura de verdad (LR) Herida en la herida, negrura de verdad (eds. ants.)

Canto XX, v. 23: no me dejan pensar. Y sé que, por la tarde, (LR) 
no me dejan pensar. Y sé que $a$ la tarde (eds. ants.) (LR)

Canto XXI, v. 19: En las venas se va desangrando aquel dios En las venas se va desangrando un dios (eds. ants.)

Canto XXIII, v. 19: mas no vibra, son brasas de ti aquellas estrellas (LR)

mas no vibra, son brasas de ti esas estrellas (eds. ants.)

Canto XXVIII, v. 12: de un camino que lleva hasta algún cementerio (eds. posteriores a la $1^{\mathrm{a}}$ )

de un camino que lleva $a$ algún cementerio ( $1^{\mathrm{a}} \mathrm{ed}$.)

Canto XXXI, v. 8: Y las manos con oro de la luz se fundieron (LR)

Y las manos de oro de la luz se fundieron (eds. ants.)

Canto XXXII, v. 3: allá, por una umbría del Valle del Silencio (LR)

allá en una umbría del Valle del Silencio (eds. ants.)

La sustitución puede afectar a más de una palabra, hasta transformar relativamente el verso, como ocurre en el canto XIII, v. 20:

Pero, a la vez, sentían en lo hondo de sus almas (LR)

Pero, al mismo tiempo, había en sus almas (eds. ants.)

La adición de palabras cumple funciones semejantes al resto de las modificaciones que suponen las correcciones: ajustar métrica y rítmicamente cada hemistiquio heptasilábico del alejandrino. Se trata, por lo general, de partículas que se añaden al verso (el, las, en, se, ya, que, y, yo, me, gran, como, etc.) para la conformación silábica del correspondiente hemistiquio, que, previamente, recurría a hiatos tal vez antinaturales para tal ajuste. Valgan los cuatro ejemplos tomados del canto II: 
v. 13: y todo es un silencio, y un presente infinito (LR) $\mathrm{y}$ todo es silencio, y presente infinitos (eds. ants.)

v. 17: hasta el cráneo y allí estalla, y me sumerge (LR) hasta el cráneo, y allí estalla, y sumerge (eds. ants.)

v. 20: firmamento en cenizas o un gran mar calcinado? (eds. posteriores a la $1^{\mathrm{a}}$ )

firmamento en cenizas o un mar calcinado? ( $1^{\mathrm{a}}$ ed. $)$

v. 25: se penetran de noche, y ya oigo derramado (LR)

se penetran de noche, y oigo derramado (eds. ants.)

La adición raramente va más allá de una partícula determindada, pero también ocurre en algún caso:

Canto XXVIII, v. 8: acuoso, enfermo, y tanta soledad ya me arrastra (LR)

acuoso, y tanta soledad me arrastra $\left(1^{\mathrm{a}} \mathrm{ed}.\right)$

Este verso había sido corregido antes, con la adición de la partícula ya a partir de la edición de Noche más allá de la noche en 1994: ${ }^{5}$ «acuoso, y tanta soledad ya me arrastra».

La inversión del orden de los elementos de la frase supone, métricamente, un recuento silábico diferente. Así, el verso inicial del canto II comenzaba con un hemistiquio que sólo puede ser heptasilábico con hiato entre las dos primeras palabras (tengo-un) o con diéresis en la última (pï-edra): «Tengo un sol de piedra / contenido en mi cráneo»; la variante por inversión del orden evita tales posibilidades, ajustando el hemistiquio a las siete sílabas cabales: «Un sol de piedra tengo / contenido en mi cráneo». Veamos algunas otras alteraciones en la ordenación de los términos del verso, de la veintena introducidas para la edición de Noche más allá de la noche en LR:

Canto XII, v. 23: el infinito yermo, un mar carbonizado (LR) el yermo infinito, un mar carbonizado (eds. ants.)

${ }^{5}$ Colinas, Antonio. 1994. El río de sombra. Poesía, 1967-1990. Madrid: Visor. 
Canto XXI, v. 24: en mi pecho clavada, herida que no duele (LR) clavada en mi pecho, herida que no duele (eds. ants.)

Canto XXX, v. 9: haremos un viaje al Sueño, sin regreso (LR) haremos un viaje, sin regreso, al Sueño (eds. ants.)

Canto XXXIV, v. 1: ¿La luz es de los dioses o la luz es un dios? (LR)

¿La luz es de los dioses o es la luz un dios? (eds. ants.)

En escasas variantes se combinan diferentes categorías modificativas, por ejemplo, adición e inversión:

Canto XXIII, v. 18:

que hoy no suenan, orquesta que allá en lo oscuro brilla (LR) que hoy no suenan, orquesta que brilla en lo oscuro (eds. ants.)

Véase el proceso de correcciones del v. 11 del canto IV hasta llegar a la solución definitiva:

Venía un aroma / de algas en las rocas ( $1^{\mathrm{a}}$ ed.)

Venía un aroma de algas / en las rocas gastadas (ed. 1999)

De las rocas llegaba / un agrio aroma de algas (LR)

En algún caso, la corrección llevó a la restauración total o parcial de uno o más versos:

Canto XX, vv. 10-11:

que, a veces, en la paz del paraíso, brotan

de los labios los versos que nos desasosiegan (LR)

que, a veces, de los labios se escapan, en la paz

de este paraíso sublime, unos versos (eds. ants.)

En todos los casos, con las correcciones propuestas, Antonio Colinas ha buscado un singular afinamiento rítmico en la

${ }^{6}$ Edición de Noche más allá de la noche en Colinas, Antonio. 1999. El río de sombra (Treinta años de Poesía, 1967-1997). Madrid: Visor. 
escansión de los hemistiquios del alejandrino, más ajustados al silabeo de la pronunciación española común, así como a los patrones métricos más usuales. De cualquier manera, no seríamos fieles al pensamiento coliniano si, tras el análisis, no trascendiéramos el sentido concreto del ritmo de los versos hacia un ritmo universal perceptible en la naturaleza, en el arte y en la poesía, que no otra cosa es ésta que una más de las manifestaciones de la armonía que rige el mundo, si bien, con la música, la más relevante para el hombre, que, con ella, contribuye a paliar la tragedia de una existencia perturbada por la lucha de contrarios.

Si Noche más allá de la noche se cierra con un "Post-scriptum" que supone la vuelta a la realidad tras el paso por las "noches" del hombre y del mundo, el final de este artículo quiere ser, contrariamente, tras la realidad del análisis del ritmo concreto de los versos, un retorno a la armonía consoladora de Orfeo.

\section{Referencias bibliográficas}

ALONSO GUTIÉRREZ, LUIS MIGUEL. 1990. El corazón desmemoriado. Claves poéticas de Antonio Colinas, León: Diputación de León.

2000. Antonio Colinas, un clásico del siglo XXI, León: Universidad de León.

CARAVAGGI, GIOVANNI. 1990. "Premesse di Noche más allá de la noche", en Ánthropos, $\mathrm{n}^{\circ}$ 105, Barcelona, febrero, II-VIII.

COLINAS, ANTONIO. 1988. "El sentido primero de la palabra poética", en El sentido primero de la palabra poética. México/Madrid: FCE, 13-32.

-1991. Tratado de armonía. Barcelona: Tusquets.

-1996. "Fray Luis de León: la música razonada", en Sobre la Vida Nueva. Oviedo: Nobel, 113-143.

-1997. "Antonio Colinas: "No podemos levantar muros entre poesía y vida" (entrevista). El ciervo, 40, mayo, "Pliego de Poesía 118".

-2001a. Del pensamiento inspirado I. Junta de Castilla y León.

-2001b. Del pensamiento inspirado II. Junta de Castilla y León.

-2001c. "Espíritu mediterráneo y creación literaria", en Colinas, Antonio, 2001a, 56-69.

-2001d. "Sobre Noche más allá de la noche", en Colinas, Antonio, 2001b, 116121.

-2001e. "Presencia y esencia de los mitos", en Colinas, Antonio, 2001a, 13-21. 
-2001f. “¿Por qué he traducido?”, en Colinas, Antonio, 2001b, 53-57.

-2001g. "La verdad trascendente de Ricardo Molina", en Colinas, Antonio, 2001a, 267-275.

—2001h. "Los símbolos originarios del escritor", en Colinas, Antonio, 2001b, 3146.

-2004. En la luz respirada (Sepulcro en Tarquinia, Noche más allá de la noche, Libro de la mansedumbre). Madrid: Cátedra (ed. de Martínez Fernández, José Enrique).

—et alii. 1997. El viaje hacia el centro (La poesía de Antonio Colinas). Madrid: Calambur.

DOMÍNGUEZ CAPARRÓS, JOSÉ. 1993. Métrica española. Madrid: Síntesis.

HUERTA CALVO, JAVIER. 1997. "Comentario de un poema de Antonio Colinas (Noche más allá de la noche, Canto X)", en Colinas, Antonio et alii. 1997, 211228; versión ampliada del artículo publicado, con el mismo título, en 1992. Foro Hispánico, no 6, Ámsterdam, 151-163.

PEREDA, ROSA MARÍA. 1983. "Antonio Colinas, o el poema que es un libro", $E l$ País, Madrid, 13 de marzo.

PUERTO, José Luis. 1997a. "Antonio Colinas: la poesía como itinerario de purificación", en Colinas, Antonio et alii. 1997, 41-70.

-1997b. "Conversación con Antonio Colinas", en Colinas, Antonio et alii. 1997, $157-171$.

VV. AA. 1994. "Coloquio con Antonio Colinas", en Trabanco, Nieves (ed.). Diálogos sobre poesía española. Frankfurt / Madrid: Vervuet Verlag / Iberoamericana, 4777. 